\title{
Tort Personal Injury Claims Statistics: Is There a Compensation Culture in the United Kingdom?
}

\author{
RICHARD LEWIS, ANNETTE MORRIS, and KEN OLIPHANT *
}

This article seeks to identify the most reliable sources of statistical information about the workings of the personal injury litigation system in the United Kingdom (UK), to present their principal data in clear, straightforward and accessible form, and to subject them to critical analysis. These figures provide the basis for an initial examination of the claim that a damaging compensation culture has developed in the $U K$ in recent years.

\section{INTRODUCTION}

At a time when the personal injury litigation system is attracting renewed attention stimulated above all by claims of a compensation culture - attempts at serious evaluation are undermined by the lack of up-to-date statistical information about its workings. ${ }^{1}$ In the UK there has been no comprehensive empirical investigation of the system since the time of the Pearson Royal Commission $(1978)^{2}$ and the personal injury survey conducted by the

* Cardiff Law School, Cardiff University, Wales, UK.

We wish to thank the editor, the anonymous referee, and our colleague, Richard Moorhead, for their comments.

${ }^{1}$ K Williams, 'State of Fear: Britain's 'Compensation Culture' Reviewed' (2005) 25 Legal Studies 499 at 513 - 4. This article relies mainly on secondary sources, and presents only a partial account of the evidence that is available. On the importance of evaluating the tort system by reference to reliable statistical data see D Dewees, D Duff, and M Trebilcock, Exploring the Domain of Accident Law: Taking the Facts Seriously, Oxford University Press, Oxford, 1996.

${ }^{2}$ Royal Commission on Compensation for Personal Injury (Chairman: Lord Pearson), Report, Cmnd 7054 (3 vols), HMSO, London, 1978. 
Oxford Centre for Social Legal Studies ("the Oxford survey”). ${ }^{3}$ A subsequent study undertaken for the Civil Justice Review was very small-scale and paid disproportionate attention to tried cases as opposed to out-of-court settlements, disqualifying it as a reliable source of empirical evidence about the personal injury litigation system as a whole. ${ }^{4}$

The purpose of the current article is to present in simple and accessible form some basic facts about the modern personal injury litigation system in the UK, drawing upon the most reliable data sources that are available. In the first part of the article ("Sources"), we identify three key sources of statistical information about claims in tort, explaining how their data is assembled and giving a brief overview of what we can learn from them, focusing on data relating to the number and cost (including the legal cost) of claims. In the second part (“Analysis"), we consider trends in these data over time, seeking to identify the major factors that may have influenced claims frequency and average claims costs. An important ulterior goal is to give at least a preliminary evaluation of the contention that both the number and the cost of claims have been driven to record levels. If the figures bear this out, it would lend support to those who consider the UK to be gripped by a compensation culture, ${ }^{5}$ and

${ }^{3}$ D Harris et al, Compensation and Support for Illness and Injury, Oxford University Press, Oxford,1984.

${ }^{4}$ See Inbucon Management Consultants, Civil Justice Review: Study of Personal Injury Litigation, Lord Chancellor's Department, London, 1986, and Civil Justice Review, Report of the Review Body on Civil Justice, Cm 394, HMSO, London, 1988.

${ }^{5}$ See, eg, F Furedi, Courting Mistrust: The Hidden Growth of a Culture of Litigation in Britain, Centre for Policy Studies, London, 1999. But cf E Lee et al, Compensation Crazy: Do We Blame and Claim Too Much? Hodder \& Stoughton, London, 2002. For an account of how the media has exaggerated the number and cost of tort claims in the USA, see W Haltom and M McCann, Distorting the Law: Politics, Media, and the Litigation Crisis, University of Chicago Press, Chicago, 2004, and for similar concerns in the context of clinical negligence see T Baker, The Medical Malpractice Myth, University of Chicago Press, Chicago, 2005. For further analysis see Williams, above n 1 and A Morris, 'Spiralling or Stabilising? The Compensation Culture and Our Propensity to Claim Damages for Personal Injury' (forthcoming). 
undermine the Government's view that, although the compensation culture is a myth, the public's erroneous belief that it exists results in real and costly burdens. ${ }^{6}$

\section{SOURCES}

Three sources relating to tort claims are examined in outline and their main findings summarised. These sources are, firstly, the data supplied in recent years by the Government's Compensation Recovery Unit concerning the total number of claims made for personal injury each year; secondly, actuarial analyses based on over a million claims and produced for successive reports commissioned by the Association of British Insurers; and finally, the detailed figures collated in relation to clinical negligence claims made against the National Health Service. A distinguishing feature of all three sources of information is that they are founded upon a very wide statistical base.

\section{COMPENSATION RECOVERY UNIT STATISTICS}

Since 1990, the Compensation Recovery Unit (CRU) has administered the scheme which enables the state to recover from tort damages any social security benefit paid as a result of a relevant accident or disease. ${ }^{7}$ An essential part of this scheme is that all compensators must provide prompt notification to CRU of any claim for personal injury made against them. As a result CRU presently holds the most comprehensive and reliable data on the number of current personal injury claims. ${ }^{8}$ It is a potentially rich source of

\footnotetext{
${ }^{6}$ The Government's view, following the conclusions of its Better Regulation Task Force in Better
} Routes to Redress, Cabinet Office Publications, London, 2004, underlies the curious provisions of the current Compensation Bill, introduced in November 2005, which simply reiterates the current test of breach of duty in negligence (clause 1), and then establishes a framework for the regulation of claims management services.

\footnotetext{
${ }^{7}$ The Unit was established by the Social Security Act 1989 and administers the scheme now provided for by the Social Security (Recovery of Benefits) Act 1997.

${ }^{8}$ It also records annual numbers of settlements, but this information is currently of limited use because there is a considerable element of double-counting of interim and final compensation payments.
} 
information about various aspects of the tort system which hitherto has received little attention, partly because only some of the information gathered has been made public.

However, there are particular difficulties in using the statistics which relate to claims made before 2000. They were not made widely available and their full details remain unknown outside of CRU. In addition, until 1997 benefits could not be recovered from damages awards of $£ 2,500$ or below, and compensators were not required to report claims that fell within this category. As a result the Department of Social Security (DSS) estimated that half of all the claims made were not reported at all. ${ }^{9}$ Therefore the earlier figures, where available, reveal only part of the compensation picture. It was only in October 1997 that the exemption for small payments was removed and the reporting requirement extended to cover all claims, no matter how small. By contrast with these earlier figures, those for current claims are very accurate because the rate of compliance with the increased reporting requirement is very high. This is partly because standardised procedures have now been built into the claims handling procedures of the insurers and other bodies who, in practice, constitute the real defendants in tort claims.

Table 1: Total Number of Claims Notified Since 2000 (Source: CRU)

\begin{tabular}{|l|l|}
\hline Year & Number \\
\hline $2000 / 2001$ & 735,931 \\
\hline $2001 / 2002$ & 688,315 \\
\hline $2002 / 2003$ & 706,697 \\
\hline $2003 / 2004$ & 770,243 \\
\hline $2004 / 2005$ & 755,875 \\
\hline
\end{tabular}

${ }^{9}$ DSS, Memorandum of Evidence to the Social Security Select Committee (1995) HC 196, para 40. 
From table 1 it can be seen that the number of claims has increased only by three per cent in the last five years. The more detailed figures in the below tables reveal that not all types of injury have reflected this small increase. In particular, it is notable that accident claims have actually declined, and it is the substantial rise in claims for disease that accounts for the overall increase.

Table 2: Number of Accident Claims Notified Since 2000 (Source: CRU)

\begin{tabular}{|r|r|c|c|c|c|c|}
\hline \multicolumn{7}{|c|}{ Number of Notifications of Accident Claims } \\
\hline & Medical & Employer & \multicolumn{1}{|c|}{ Public } & Motor & Other & Total \\
\hline $\mathbf{0 0 / 0 1}$ & 10,980 & 97,675 & 94,000 & 401,740 & 7,815 & 612,120 \\
\hline $\mathbf{0 1 / 0 2}$ & 9,773 & 97,004 & 100,663 & 400,434 & 6,252 & 614,126 \\
\hline $\mathbf{0 2} / \mathbf{0 3}$ & 7,973 & 92,915 & 109,441 & 398,870 & 6,347 & 615,546 \\
\hline $\mathbf{0 3 / 0 4}$ & 7,109 & 79,286 & 91,177 & 374,740 & 4,874 & 557,186 \\
\hline $\mathbf{0 4 / 0 5}$ & 7,196 & 77,765 & 86,966 & 402,892 & 4,463 & 579,282 \\
\hline
\end{tabular}

Table 2 reveals that in the past five years there has been a five per cent fall in the overall number of accident claims. Whereas the number of motor claims has remained remarkably stable, clinical negligence claims have fallen by 34 per cent employers' liability by 21 per cent, and public liability by seven per cent. Motor claims comprise almost 70 per cent of the total.

Table 3: Number of Disease Claims Notified Since 2000 (Source: CRU)

\begin{tabular}{|c|c|r|r|r|c|c|}
\hline \multicolumn{7}{|c|}{ Number of Notifications of Disease Claims } \\
\hline & Medical & Employer & Public & Motor & Other & Total \\
\hline $\mathbf{0 0 / 0 1}$ & 11 & 121,508 & 1,883 & 17 & 392 & 123,811 \\
\hline
\end{tabular}




\begin{tabular}{|c|c|c|c|c|c|c|}
\hline $\mathbf{0 1 / 0 2}$ & 6 & 73,550 & 326 & 11 & 296 & 74,189 \\
\hline $\mathbf{0 2 / 0 3}$ & 4 & 90,427 & 341 & 22 & 357 & 91,151 \\
\hline $\mathbf{0 3 / 0 4}$ & 12 & 211,924 & 276 & 21 & 824 & 213,057 \\
\hline $\mathbf{0 4 / 0 5}$ & 9 & 175,737 & 281 & 32 & 544 & 176,603 \\
\hline
\end{tabular}

The number of notifications of disease claims has fluctuated widely. Numbers dropped by over a quarter in the three years to 2003 , but in the next year claims more than doubled. Although they again declined last year, they were still 42 per cent higher than five years previously. An explanation for this is given in the analysis section in the second part of this article.

\section{Overall Number of Claims Before 2000}

In the year October 1996 to September 1997 there were just over 30,000 notifications of claims each month, the total for the year being $361,819 .{ }^{10}$ This was at a time when the notification requirement was more limited because of the exemption for small payments of damages. When the limitation was removed in October 1997, notifications immediately doubled to over 58,000 a month, and amounted to 705,232 in the year to September 1998. However, the significant feature to note is that claims have not increased substantially since that time. The 1997-98 figure is almost the same as that recorded for 2002-03. It is true that claims increased in the following two years. However, the increase was at most about ten per cent and if we were to discount the figures relating to diseases (which rose for particular short-term reasons) we would find that tort claims have actually declined in number.

\section{THE INSURERS' BODILY INJURY AWARDS STUDIES}

\footnotetext{
${ }^{10}$ The figures in this section are derived from an internal memorandum of the Department of Social Security. These and related figures are discussed in R Lewis, Deducting Benefits From Damages For Personal Injury, Oxford University Press, Oxford, 1999, ch 14.
} 
Commissioned by the Association of British Insurers and by the International Underwriting Association of London, three successive reports have been published into claims received by insurers for compensation for personal injury resulting from use of motor vehicles. ${ }^{11}$ The first report appeared in 1997, the second in 1999, and the most recent in 2003. They investigate injury claims trends in the UK and the forces that affect them.

The studies claim to be the biggest exercise of their kind ever undertaken. Although the accounts they give of the changes in the law and legal system are unexceptional, it is certainly true that the actuarial analyses has been carried out using a very wide statistical base: for the third report 1.1 million personal injury claims made against motor insurers were analysed, the information being obtained from insurers representing 90 per cent of the overall motor insurance market. Relying in part upon the earlier reports, the 2003 report produces figures which cover motor accidents which occurred between 1991 and 2000, and consists of 208 pages of statistics and commentary.

However, the reports do not cover claims made other than against insurers, nor do they deal with injuries other than those involving a motor vehicle. Unlike the Compensation Recovery Unit statistics, therefore, the reports do not attempt to be comprehensive of all personal injury claims (or even of insured personal injury claims) and neither do they focus on very precise claims figures for any particular year.

\section{Claim Frequency}

Table 4 below reveals that claim frequency - the number of claims made in relation to the number of policies issued - increased by an average of 3 per cent a year from 1991-2000, even though it fell by an average of 4.1 per cent a year in 1999 and 2000. The fall was due to a decline in very small claims. The standardised index in the below table shows the

\footnotetext{
${ }^{11}$ London International Insurance and Reinsurance Market Association (LIRMA), UK Bodily Injury Awards Study, LIRMA, London, 1997, International Underwriting Association of London (IUAL), Second UK Bodily Injury Awards Study, IUAL, London, 1999), and IUAL, Third UK Bodily Injury Awards Study, IUAL, London, 2003.
} 
changes in claims frequency compared to that experienced in 1992, that year being taken as the base year for present purposes.

Table 4: Frequency of Personal Injury Claims from Motor Vehicle Use (Source:

\section{LIRMA/IUAL)}

\begin{tabular}{|c|c|c|}
\hline Loss Year & $\begin{array}{c}\text { Standardised } \\
\text { claim frequency } \\
\text { index }\end{array}$ & $\begin{array}{c}\text { Percentage } \\
\text { change in } \\
\text { index }\end{array}$ \\
\hline $\mathbf{1 9 9 1}$ & 98.3 & - \\
\hline $\mathbf{1 9 9 2}$ & 100 & 1.8 \\
\hline $\mathbf{1 9 9 3}$ & 94.7 & -5.3 \\
\hline $\mathbf{1 9 9 4}$ & 101.2 & 6.8 \\
\hline $\mathbf{1 9 9 5}$ & 103.8 & 2.6 \\
\hline $\mathbf{1 9 9 6}$ & 116.4 & 12.1 \\
\hline $\mathbf{1 9 9 7}$ & 128.8 & 10.7 \\
\hline $\mathbf{1 9 9 8}$ & 139.7 & 8.4 \\
\hline $\mathbf{1 9 9 9}$ & 133.4 & -4.5 \\
\hline $\mathbf{1 9 9 8 - 2 0 0 0}$ & & -4.1 \\
\hline & & 5.1 \\
\hline & & \\
\hline & & \\
\hline & & \\
\hline $\mathbf{1 9 9 1 - 1 9 9 8}$ & & \\
\hline
\end{tabular}




\section{Claim Severity}

Table 5 below reveals that claims severity - the average cost of each claim made - increased by an average of 6.7 per cent a year from 1991-2000, with very marked increases in the last two years. Again the standardised index is set with 1992 as the base year.

Table 5: Severity of Personal Injury Claims from Motor Vehicle Use (Source:

\section{LIRMA/IUAL)}

\begin{tabular}{|c|c|c|}
\hline Loss Year & $\begin{array}{c}\text { Standardised } \\
\text { claim severity } \\
\text { index }\end{array}$ & $\begin{array}{c}\text { Percentage } \\
\text { change in } \\
\text { index }\end{array}$ \\
\hline $\mathbf{1 9 9 1}$ & 94.7 & - \\
\hline $\mathbf{1 9 9 2}$ & 100 & 5.6 \\
\hline $\mathbf{1 9 9 3}$ & 100.9 & 0.9 \\
\hline $\mathbf{1 9 9 4}$ & 100 & -0.8 \\
\hline $\mathbf{1 9 9 5}$ & 109.3 & 9.2 \\
\hline $\mathbf{1 9 9 6}$ & 123.0 & 12.6 \\
\hline $\mathbf{1 9 9 7}$ & 127.1 & 3.4 \\
\hline $\mathbf{1 9 9 8}$ & 132.4 & 4.2 \\
\hline $\mathbf{1 9 9 9}$ & 153.0 & 15.6 \\
\hline $\mathbf{1 0 9 0}$ & 169.0 & 6.7 \\
\hline $\mathbf{1 9 9 1 - 1 9 9 8}$ & & \\
\hline
\end{tabular}




\begin{tabular}{|l|l|l|}
\hline 1998-2000 & & 13.0 \\
\hline
\end{tabular}

\section{Burning Costs}

Burning cost is a term widely used in the insurance industry to represent the claim cost per policy. It is made up of a combination of claim frequency and claim severity, that is, in effect Tables 4 and 5 above. Table 6 below again uses 1992 as the base year and reveals that the cost per policy increased by an average of 9.9 per cent a year from 1991 - 2000, as against an average rise in national earnings of 4.2 per cent. As compared with 1991, claims cost in 2000 had risen by 133 per cent compared to a rise in national average earnings of 45 per cent. However, from 1998 the rise in burning costs was much less steep and was only 6.6 per cent in 2000 . This reflected the drop in claim frequency, although claim severity continued to increase. Although claim frequency declined in these later years, it was still 29 per cent higher than it was in 1992.

Table 6: Burning Cost of Personal Injury Claims from Motor Vehicle Use (Source: LIRMA/IUAL)

\begin{tabular}{|c|c|c|c|}
\hline Loss Year & $\begin{array}{c}\text { Standardised } \\
\text { burning costs } \\
\text { index }\end{array}$ & $\begin{array}{c}\text { Percentage } \\
\text { change in } \\
\text { index }\end{array}$ & $\begin{array}{c}\text { Percentage } \\
\text { change in } \\
\text { national average } \\
\text { earnings index }\end{array}$ \\
\hline $\mathbf{1 9 9 1}$ & 93.0 & - & - \\
\hline $\mathbf{1 9 9 2}$ & 100 & 7.5 & 6.0 \\
\hline $\mathbf{1 9 9 3}$ & 95.5 & -4.5 & 3.1 \\
\hline $\mathbf{1 9 9 4}$ & 101.2 & 5.9 & 3.6 \\
\hline $\mathbf{1 9 9 5}$ & 113.4 & 12.1 & 3.1 \\
\hline
\end{tabular}




\begin{tabular}{|c|c|c|c|}
\hline $\mathbf{1 9 9 6}$ & 143.2 & 26.2 & 3.6 \\
\hline $\mathbf{1 9 9 7}$ & 163.7 & 14.4 & 4.2 \\
\hline $\mathbf{1 9 9 8}$ & 184.9 & 12.9 & 5.2 \\
\hline $\mathbf{1 9 9 9}$ & 204.1 & 10.4 & 4.8 \\
\hline $\mathbf{2 0 0 0}$ & 217.2 & 6.4 & 4.8 \\
\hline $\mathbf{1 9 9 1 - 2 0 0 0}$ & & 9.9 & 4.2 \\
\hline $\mathbf{1 9 9 1 - 1 9 9 8}$ & & 10.3 & 4.1 \\
\hline $\mathbf{1 9 9 8 - 2 0 0 0}$ & & 10.4 & 3.5 \\
\hline
\end{tabular}

\section{Legal Costs}

Throughout the period studied legal costs, including both claimant and defendant costs, averaged 30 per cent of total motor personal injury payments. This means that legal costs continued to increase by more than double the rate of the rise in national average earnings.

\section{NATIONAL HEALTH SERVICE STATISTICS}

The proper recording of National Health Service (NHS) clinical negligence compensation costs began only in 1996. Details of annual NHS expenditure on clinical negligence claims in England may be found in the annual NHS accounts ${ }^{12}$ for the period from 1996 to 2002, at which date the NHS Litigation Authority (NHSLA) took over full responsibility for all such claims. The NHSLA's staged "call in" of existing NHS claims made against the primary care trusts before 2002 prevents meaningful comparison of its own figures over time, but combined with information in the NHS accounts, they allow comparison from 1996

\footnotetext{
${ }^{12}$ Available online from www.nao.org.uk.
} 
onwards of the total compensation costs in England. From 2002 the NHSLA statistics provide a complete picture of clinical negligence claims volumes and costs.

Before 1996 the picture is incomplete, with a limited amount of information available in official reports, ${ }^{13}$ answers to parliamentary questions, and various independent studies. ${ }^{14}$ It is difficult to make comparisons because of the differences in the methods employed, but some information about trends may be drawn from Fenn et al.'s longitudinal study of negligence claims arising from treatment in the Oxfordshire health authority area from the early 1980s to 1999. ${ }^{15}$

\section{Number of Claims}

There has undoubtedly been a very great increase in clinical negligence claims in the last 30 or so years. The Pearson Commission reported in 1978 that the number of claims of malpractice against doctors and dentists (including those in private practice) had been running at about 500 a year. ${ }^{16}$ By 1990-91, the estimated number of new medical negligence claims made against the NHS in England had risen to between 5419 and 6979

\footnotetext{
${ }^{13}$ National Audit Office, Handling Clinical Negligence Claims, HC 403, Session 2000-2001, The Stationery Office, London, 2001, and Department of Health, Making Amends: A consultation paper setting out proposals for reforming the approach to clinical negligence in the NHS (A report by the
} Chief Medical Officer), Department of Health Publications, London, 2003.

\footnotetext{
${ }^{14}$ See C Ham, R Dingwall, P Fenn and D Harris, Medical Negligence: Compensation and
} Accountability, King's Fund Institute, London, 1988; P Fenn, D Hermans and R Dingwall, 'Estimating the cost of compensating victims of medical negligence' (1994) 309 BMJ 389, and P Fenn, S Diacon, A Gray, R Hodges, N Rickman, 'Current cost of medical negligence in NHS hospitals: analysis of claims database' (2000) 320 BMJ 1567. The earlier research, and more recent NHSLA data, are considered further in P Fenn, A Gray and N Rickman, 'The Economics of Clinical Negligence Reform in England' (2004) 114 The Economic Journal F272.

\footnotetext{
${ }^{15}$ Fenn, Diacon et al, above n 14.

${ }^{16}$ Pearson, above n 2, vol 1, para 1318.
} 
for the year. ${ }^{17}$ The Oxfordshire study reported a "steady growth" in new claims in the period 1974-98. In answers to Parliamentary questions in 2005, the number of claims made from 1996-2004 was broken down as follows, using information supplied by the NHSLA: ${ }^{18}$

Table 7: Total Number of Clinical Negligence Claims Reported (Source: Hansard)

\begin{tabular}{|c|c|}
\hline $1996-97$ & 4,136 \\
\hline $1997-98$ & 6,932 \\
\hline $1998-99$ & 6,916 \\
\hline $1999-2000$ & 7,036 \\
\hline $2000-01$ & 6,915 \\
\hline $2001-02$ & 7,215 \\
\hline $2002-03$ & 6,257 \\
\hline $2003-04$ & 4,844 \\
\hline
\end{tabular}

These figures confirmed the "continuation of the downward trend" in claims numbers that has been evident in recent years. ${ }^{19}$ They now are close to the lowest estimate for the year 1990-91, coming down from a peak in the period 1997-2002.

\footnotetext{
${ }^{17}$ Fenn, Hermans and Dingwall, above n 14.

18 J Kennedy, Hansard HC vol 435 col 1342W (27 June 2005) and col 1501W (28 June 2005)
}

${ }^{19}$ NHSLA, Report and Accounts 2005, HC 149, The Stationery Office, London, 2005, p 13. 


\section{Claims Settled and Closed}

The NHSLA's analysis of all clinical negligence claims handled since its inception in 1995 reveals that 45 per cent were abandoned by the claimant and 52 per cent settled out of court; 2 per cent were concluded by a court judgment for the claimant (including court approvals of settlements negotiated on behalf of children); and 0.6 per cent by judgment for the NHS. ${ }^{20}$ In 2004-05 the NHSLA "closed" a total of 8,393 claims (irrespective of whether or not they closed with the payment of damages or costs). ${ }^{21}$ Assuming half or more involved the payment of damages, the number of "settled" claims (including those resolved in court) has clearly risen significantly from the early 1990s, when it was reported that 1618 and 1751 claims had been settled in 1990-91 and 1991-92 respectively. ${ }^{22}$ This is further confirmed by the finding of the Oxfordshire study that the number of closed claims more than doubled in the period 1990-98, with the rate of closed cases per 1000 finished consultant episodes rising from 0.46 in 1990 to 0.91 in 1998, a rate of increase of about 7 per cent a year. ${ }^{23}$ These increases are not matched by comparable increases in the number of new claims over that period, and it seems likely that they reflect a rise in the number of new claims made before 1990 but taking several years to settle.

\section{Cost of Claims}

A complete picture of the NHS's annual expenditure on clinical negligence compensation in England is available from $1996 .^{24}$ This reveals a general upwards trend up to and including the year 2004-05. The figures are startlingly higher than those available for the start

\footnotetext{
${ }^{20}$ Figures from www.nhsla.com (accessed 10 August 2005), recalculated to exclude outstanding claims).

${ }^{21}$ NHSLA, above n 19, p 17.

${ }^{22}$ B Mawhinney, Hansard HC vol 239 col 538 (14 March 1994 WA).

${ }^{23}$ Fenn, Diacon et al, above n 14.

${ }^{24}$ Sources: NHS (England) annual accounts; NHSLA, above n 19; Department of Health, above n 13, para 35 (table).
} 
of the 1990s, when the annual cost of clinical negligence compensation was reported to have been $£ 53.2 \mathrm{~m}$ and $£ 51.3 \mathrm{~m}$ in 1990-91 and 1991-92 respectively. ${ }^{25}$ Even these are very much higher than the estimated figure for $1974-75$ of $£ 1 \mathrm{~m} .{ }^{26}$ In claims for clinical negligence that were closed by the NHSLA in 2004-05, defence and claimant costs were equal to, respectively, 13.76 per cent and 19.81 per cent of damages. ${ }^{27}$

Table 8: Total Payments Made by the NHS for Clinical Negligence 1996- 2005 (Source: NHS/NHSLA)

\begin{tabular}{|c|c|}
\hline Year & f million \\
\hline $1996-97$ & 235 \\
\hline $1997-98$ & 144 \\
\hline $1998-99$ & 221 \\
\hline $1999-2000$ & 373 \\
\hline $2000-01$ & 415 \\
\hline $2001-02$ & 446 \\
\hline $2002-03$ & 446 \\
\hline $2003-04$ & 423 \\
\hline $2004-05$ & 503 \\
\hline
\end{tabular}

\footnotetext{
${ }^{25}$ Mawhinney, above n 22.

${ }^{26}$ Department of Health, above n 13, p 60 (table).

${ }^{27}$ NHSLA, above n 19, p 17 (table).
} 


\section{Outstanding Liabilities for Clinical Negligence}

One of the most frequently misapplied statistics in the current compensation culture debate is the annual estimate of the NHS's outstanding liabilities for clinical negligence (including both known and unknown but expected claims, and taking into account the likelihood of settlement). This has risen from £3.2 billion in 1999 to $£ 5.9$ billion in 2003 and $£ 7.8$ billion in 2004 . The figures refer to liabilities that the NHS claims will arise over a long period of time, and are very much greater than the sums that are actually paid out on an annual basis. Estimating the cost of outstanding liabilities is an exercise that is fraught with difficulties and the resulting figure representing a "worst case" scenario has been heavily criticised. ${ }^{28}$ Although the estimate of outstanding liabilities is frequently cited in the press and media, it must be handled with care. It would be quite wrong, for example, to use it to calculate the percentage of the annual NHS budget that is currently spent on clinical negligence compensation.

\section{OTHER SOURCES}

In addition to the three primary sources we have relied upon in this article, we have also derived useful information from elsewhere, and it may be helpful to make a brief note of our other sources. Statistical information about compensation claims against the Ministry of Defence $(\mathrm{MoD})$ is to be found in a report by the National Audit Office in 2003. ${ }^{29}$ Members of the armed forces were first allowed to pursue actions for damages against the $\mathrm{MoD}$ in $1987,{ }^{30}$ and the report inevitably charts a considerable rise in the volume of litigation over

\footnotetext{
${ }^{28}$ Fenn, Diacon et al, above n 14, P Fenn, 'Counting the Cost of Medical Negligence' (2002) 325 BMJ 233, and Fenn, Grey and Rickman above n 14, and D Marshall, 'Dressing Up The Figures?' (2002) 152 NLJ 1632.

${ }^{29}$ National Audit Office, Ministry of Defence: Compensation Claims, HC 957 Session 2002-2003, The Stationery Office, London 2003.

${ }^{30}$ Crown Proceedings (Armed Forces) Act 1987.
} 
the period it surveys, reflecting the build up of claims from zero. Of more interest to us is the substantial rise in MoD compensation costs - and legal costs in particular - in the four years from 1998-1999. Legal costs as a percentage of damages rose from 14.1 per cent in 19981999 to 18.5 per cent in 2001-2002. ${ }^{31}$ Confirmation that increases in legal costs have occurred in other contexts as well is to be found in two commissioned studies by Fenn and Rickman, dealing with low-value road traffic accident and employers' liability claims. ${ }^{32}$

Claimants injured by uninsured or unidentified motor vehicles are able to claim compensation from the Motor Insurers Bureau (MIB), a reserve body financed by a levy upon all motor insurers in the market. The number of claims submitted to the MIB are published in its annual reports. ${ }^{33}$ There has been a rise from about 40,000 in 1995 to about 75,000 in 2003. In the same period, amounts paid out to successful claimants rose from under $£ 100$ million to almost $£ 240$ million. Another relevant source, though not strictlyspeaking a part of the tort system, is the Criminal Injuries Compensation Authority (CICA), which reports annually on the number of applications submitted to the Criminal Injuries Compensation Scheme. ${ }^{34}$ Since the scheme's establishment in 1964, applications have increased steadily every year, rising from an average of 4,000 or so in the 1960 s to 15,000 in the $1970 \mathrm{~s}, 35,000$ in the $1980 \mathrm{~s}, 70,000$ in the 1990s, and around 75,000 in more recent years. It is impossible to specify the effect on these numbers of the various changes in the

\footnotetext{
${ }^{31}$ National Audit Office, above n 29, p 13 fig 6.

${ }^{32}$ P Fenn and N Rickman, Costs of Low Value RTA Claims 1997-2002: A Report Prepared for the Civil Justice Council, 2003, and P Fenn and N Rickman, Costs of Low Value Employers' Liability Claims 1997-2002, Department for Constitutional Affairs, London, 2003.
}

\footnotetext{
${ }^{33}$ The MIB's most recent annual reports are available from www.mib.org.uk. See also Association of British Insurers, Response of the Association of British Insurers on behalf of the MIB to the Greenaway Review of Compulsory Motor Insurance and Uninsured Driving, 2004.

${ }^{34}$ The Authority's most recent annual reports are available from www.cica.gov.uk. See also National Audit Office, Compensating Victims of Violent Crime, HC 398 Session 1999-2000, The Stationery Office, London, 2000.
} 
scope of the scheme, and the entitlements available under it, that have taken place over the scheme's history.

None of the above sources of information about personal injury claims provides anything like as broad or significant a data set as those derived from our three principal sources, but they nevertheless provide useful supporting evidence of various trends that are the subject of our analysis below.

\section{ANALYSIS}

\section{THE FREQUENCY OF CLAIMS}

According to the CRU statistics, the total number of personal injury claims has risen in three out of the last four years for which statistics are available. However, it would be simplistic to treat this as evidencing an upwards trend in the volume of personal injury litigation, for the reasons set out below. Firstly, there has been no growth in the number of claims of accidental injury in the last five years or so. This is broadly substantiated by each of our three principal sources. In fact, there has been, if anything, a downwards trend in the volume of new accident claims.

Secondly, by way of contrast there have been wild fluctuations in the number of disease claims in the same period, and these have meant that the total number of personal injury claims has shown certain year-on-year increases even where the number of accident claims has declined. At the same time, the number of new disease claims was hugely inflated in the period 1999-2004 by the Coal Health compensation schemes for vibration white finger and respiratory disease which together accounted for almost all new disease claims notified to CRU in that period. These claims, many referring to events several decades ago, have significantly skewed total personal injury claims figures in recent times, particularly in the runup to the schemes' cut off dates in 2002 and 2004. Since 1999 some 750,000 of these coalmining claims have been registered. They have been said to constitute "the biggest 
personal injury schemes in British legal history and possibly the world". ${ }^{35}$ To date, a total of $£ 2.8$ billion has been paid in compensation, with many cases yet to be finally resolved and it is estimated that the total compensation bill will exceed $£ 7.5$ billion. With no new claims now being registered it can be anticipated that there will be a substantial decline in the number of disease claims notified to CRU.

Although recent years have shown a degree of stability in the total number of claims, this follows a substantial rise in claims in preceding years: numbers increased considerably in the period following Pearson and the Civil Justice Review. The Pearson Commission estimated that in 1973 there were approximately 250,000 personal injury claims pursued through the tort system. $^{36}$ The Civil Justice Review estimated that there were approximately 340,000 claims in $1988 .{ }^{37}$ Since then, as shown by the statistics in the first part of this article, total claims numbers have continued to rise, though they seem now to have stabilised around 700-750,000 per year (approximately 600,000 are for injuries by accident). ${ }^{38}$ But this pattern is not apparent in every category of claim. The number of employers' liability claims, for example has fallen well under 100,000 a year, reflecting the decline of heavy industry and manufacturing processes traditionally associated with illness and injury caused by work. What is noticeable, however, is the dramatic rise in the number of other types of claims: motor vehicle claims now run at close to four times the 1973 figure; public liability claims

${ }^{35}$ http://www.dti.gov.uk/coalhealth/01.htm

${ }^{36}$ Pearson, above n 2, vol 2, para 59. The estimate is based on an analysis of all personal injury claims $(8,275$ in total) received by insurers who belonged to the British Insurance Association (BIA) in a four-week period in November 1973, combined with data from court records and other sources. BIA members accounted at that time for about 88 per cent of all personal injury claims in tort, and 94 per cent of their total value. See Pearson, above n 2, vol 2, ch 22.

${ }^{37}$ Civil Justice Review, above n 4, para 391. This estimate is only stated, with no indication of its factual substratum, and does not appear to be derived from the Review's own commis sioned research into personal injury claims: see Inbucon, above n 4.

\footnotetext{
${ }^{38}$ A similar long term trend is also evident in the number of claims processed each year by the Criminal Injuries Compensation Authority.
} 
(not recorded as such by Pearson) are at least twice as numerous as in 1973, and clinical negligence claims are about 100 times the 1973 level (albeit from a much lower starting point).

The increased frequency of claims since Pearson and prior to the current period of relative stability is likely to be attributable to a wide variety of factors. At one end of the spectrum, increased social understanding of injuries and their causes has meant that we are more likely to characterise symptoms as injuries and to attribute responsibility for that injury to another individual or entity. For example, it is now common knowledge that whiplash can result from a road traffic accident and indeed insurers have suggested that as many as 80 per cent of all road accident claims involve a claim for whiplash injury. ${ }^{39}$ At the other end of the spectrum, there has been an extension in the number of people who can qualify for compensation through the tort system. This is in part a consequence of legal developments. For example, liability for psychiatric harm, consequent upon involvement in or witnessing an accident has been widened in crucial respects, ${ }^{40}$ and the Motor Insurers' Bureau uninsured drivers' agreement has extended the categories of claims for which it (and indirectly the insurance industry) is responsible. ${ }^{41}$ In addition, the Crown Proceedings (Armed Forces) Act 1987 allowed service personnel to claim for the first time against the Ministry of Defence. As a result in 2001-2002 there were 7,700 claims against the Ministry of Defence, costing a total of $£ 97$ million, including legal fees, the amount having risen almost fourfold from $£ 25$ million in $1992-93 .^{42}$ Revealingly, the MoD was then facing claims from 2,000 former personnel as a result of alleged negligence in preventing, managing or treating psychological reactions to combat since 1969.

\footnotetext{
${ }^{39}$ Datamonitor, UK Personal Injury Litigation 2003 - Where Does the Industry Go From Here? London, 2003 p 45 and Datamonitor, UK Personal Injury Litigation - Trial and Error London, 2004 p 38.

${ }^{40}$ For example, in McLoughlin v O’Brian [1983] AC 410 and Page v Smith [1996] 1 AC 155.

${ }^{41}$ Both the uninsured and untraced drivers agreements have been extended in recent years. The changes are noted on the MIB website at http://www.mib.org.uk/Default.htm

${ }^{42}$ National Audit Office, above n 29.
} 
It is not only, however, that the law has expanded but also that the increased specialisation of lawyers in personal injury claims has enabled them to become increasingly adept at identifying and developing grounds for pursuing claims within the current legal framework. The founding of the Association of Personal Injury Lawyers in 1990 and its subsequent activity reflects the increasing abilities and resources of claimant lawyers. The Association now has over 5,250 members, employs 28 people, and has a turnover of $£ 1.94$ million. It helps co-ordinate claims and share expertise. This has undoubtedly facilitated a number of prominent group actions in recent years.

The reasons underlying our increased propensity to respond to injury by seeking legal redress are likely to be numerous, complex and inter-related. Perhaps the most important factor is the increased social awareness of the possibility of claiming compensation following an accident. Both the Pearson Commission and the Oxford survey found that many injured people did not claim because they did not appreciate that they could do so. $^{43}$ As knowledge has increased, therefore, so has the number of people who can identify that they have a potential claim. Increased knowledge does not just increase our ability to identify a claim, however, but may also increase our willingness to claim. Lloyd-Bostock's research in the context of the Oxford survey suggested that once we are aware that compensation is available, we become more likely to interpret and reinterpret events in such a way as to justify claiming. ${ }^{44}$ Increased levels of social awareness may also raise our expectations of recovering compensation following an injury, thereby increasing the sense of entitlement to compensation, whilst at the same time creating the sense that claiming is acceptable and routine and not a privilege to be rarely used. Greater social awareness provides, therefore, both the opportunity and the motivation for greater levels of claiming. Our increased assertiveness is unlikely, however, just to stem from increased social awareness and is probably also due to changes in our relationships with, and in our expectations of, each

\footnotetext{
${ }^{43}$ Pearson, above n 2, vol 2, table 84 and Harris et al, above n 3, pp 70-6.

${ }^{44}$ S Lloyd-Bostock, 'Fault and Liability for Accidents: The Accident Victim's Perspective', in Harris et $a l$, above $\mathrm{n} 3$.
} 
other, our employers and the state. Another possible factor, for which we have not been able to test, is changes over time in the value of and entitlement to social security benefits.

It must be emphasised that, contrary to popular belief, the introduction of conditional fee agreements (CFAs) and the advent of widespread advertising by the claims industry have not increased the frequency of claims to any significant extent. CFAs allow lawyers to act for personal injury claimants on a no-win no-fee basis. This means that $\mathrm{f}$ the claim is unsuccessful, the claimant is not liable to pay his or her own lawyer for the work done. However, liability to pay the costs of the other side remains, and to protect against this, claimants entering CFAs usually purchase after-the-event (ATE) legal expenses insurance. Where the claim is successful, although the claimant is liable to pay his or her own lawyer for the work done plus a 'success fee' for taking the risk of losing the case, these costs (including the success fee) can be recovered from the defendant. The financial risks of claiming have therefore been substantially reduced.

The use of CFAs became widespread after April 2000 with the implementation of the Access to Justice Act 1999. The Act withdrew legal aid for the majority of personal injury claims on the assumption that they could be funded by CFAs instead. The no-win no-fee no-risk aspect of CFAs is perceived to have led to a 'no reason not to sue' attitude. As noted above, however, the frequency of accident claims has remained relatively stable since April 2000. It is true that CFAs were introduced in 1995 to facilitate access to justice for those who neither qualified for legal aid nor could afford to fund their claims privately. They may, therefore, have contributed to the long-term increase in the frequency of claims evident before 1997-1998. CFA studies have suggested, however, that the take up of CFAs was relatively slow before this date. ${ }^{45}$ Similarly, lawyers have been able to advertise their services since the mid-1980s and their advertising is likely to account for increased levels of

\footnotetext{
${ }^{45}$ S Yarrow, The Price of Success: Lawyers, Clients and Conditional Fees, Policy Studies Institute, London, 1997, J Shapland et al, Affording Civil Justice, Law Society, London, 1998, and P Fenn, Gray, N Rickman and Carrier, The Impact of Conditional Fees on the Selection, Handling and Outcomes of Personal Injury Cases, Lord Chancellor's Department, 2002.
} 
social awareness. ${ }^{46}$ Widespread advertising in national papers, on television and on the radio has, however, been a significant feature since the mid-to-late 1990s with the rapid growth of claims intermediaries. Claims advertising may, therefore, have contributed to the upward trend in claims evident before 1997-1998 but it has not led to a continuing increase in the frequency of claims.

\section{THE COST OF CLAIMS}

The cost of individual claims has risen sharply in recent years and appears to be due to increases in both damages paid and legal costs incurred. Damages are likely to have increased for a number of reasons:

- Firstly, the decision in Heil $v$ Rankin increased damages for non-pecuniary loss in order to bring such awards in line with inflation. ${ }^{47}$ The effect of this judgment was to increase the highest levels of award for pain and suffering by one third from $£ 150,000$ to $£ 200,000$. Awards below $£ 10,000$ were not increased but tapered increases were applied for injuries falling between $£ 10,000$ and the highest awards. The Department of Health estimated that, because of the disproportionate number of high value claims brought against the NHS, this judgment would cost it $£ 74$ million in future liabilities. ${ }^{48}$ Given that the vast majority of general claims in tort are below $£ 10,000$, however, the impact of Heil v Rankin should not be exaggerated. ${ }^{49}$

- Of much more importance is the second reason. This is that damages have increased as a result of the reduction in the discount rate applied to future

\footnotetext{
${ }^{46}$ Solicitors were first allowed to advertise in 1984, after amendment of the Law Society's Practice Rules.

${ }^{47}$ [2001] QB 272

${ }^{48}$ Department of Health, above n 13.

${ }^{49}$ R Lewis, 'Increasing the Price of Pain' (2001) 64 MLR 100.
} 
pecuniary losses. The rate makes allowance for the investment return upon lump sum damages. For thirty years prior to 1998 the rate was 4.5 per cent but this was then reduced by the House of Lords in Wells $v$ Wells to 3 per cent. ${ }^{50}$ In 2001 the Lord Chancellor used his power to reduce the rate still further to 2.5 per cent. ${ }^{51}$ As a result of the last change alone, the NHS predicted an increase in their liabilities of $£ 100$ million a year, being about a quarter of its total expenditure on damages for clinical negligence at that time. Apart from a $£ 4$ million increase in the value of $\mathrm{MoD}$ claims, other Government departments and local authorities predicted that the effect would be negligible as they mainly dealt with relatively minor slips and trips. Although the effect upon the insurance industry was substantial, the Association of British Insurers was much more conservative in its estimates than the NHS. It predicted an increase of only $£ 57$ million in the annual bill, ${ }^{52}$ even though it pays out six times as much in claims for damages over $£ 100,000$ compared to the NHS. ${ }^{53}$

- Thirdly, the use of the Ogden tables,${ }^{54}$ which was approved by the House of Lords in Wells $v$ Wells, has increased the multipliers applied in claims and, therefore, the level of damages paid. The multipliers in the Ogden tables provide an aid for those assessing the current capital value of future pecuniary losses or expenses on the basis of various assumptions, including rates of mortality. Whilst they used to be based on historical mortality rates, they are now based on reasonable estimates of future mortality. In effect, the forecast that those living

\footnotetext{
${ }^{50}[1999] 1$ AC 345.

${ }^{51}$ Damages (Personal Injury) Order, SI 2001/2301.

${ }^{52}$ Department for Constitutional Affairs, Damages Act 1996: Analysis of the Impact of the Prescribed

Discount Rate of 2.5 per cent, 2002.

${ }^{53}$ Lord Chancellor's Department, Courts Bill: Regulatory Impact Assessment, 2002.

${ }^{54}$ Government Actuary's Department, Actuarial Tables For Use In Personal Injury And Fatal Accident Cases, $5^{\text {th }}$ ed, The Stationery Office, London, 2004 ("the Ogden Tables").
} 
today will survive longer than their forebears increases the cost of compensating them for life.

- Fourthly, damages have also increased due to the introduction of legislation which has considerably increased compensators' liability to pay for the claimant's social security benefits and NHS hospital charges. Since 1990 the state has been able to recover benefits paid to the claimant as a result of an accident in which damages for personal injury are paid. The scheme, administered by CRU, was extended in 1997 so as to apply to all cases no matter what the level of damages involved. ${ }^{55}$ Two years later another Act introduced a similarly centralised and efficient system for the recovery of NHS charges in road traffic accident claims. Prior to this, NHS costs were recovered by individual hospitals many of which did not use their powers and recovered very little. This scheme has also since been extended. Fixed sums have been set for the recovery of ambulance and care costs, and these will soon apply to all types of accident. ${ }^{56}$

- Finally, a large part of the damages award reflects income. Not only lost wages themselves but also those costs of care which reflect income levels have increased at rates well above inflation in prices. On average, real earnings growth has exceeded price inflation by almost two per cent a year for almost the last sixty years. ${ }^{57}$ As a result, it is to be expected that damages in serious injury cases will rise in real terms, but not that they will increase at more than double the rise in national earnings as the insurers bodily injury study showed.

In our study of the figures produced both by the insurance industry and in relation to the NHS, legal costs amount to approximately 30 per cent of the total tort payments. They have

\footnotetext{
${ }^{55}$ The Social Security (Recovery of Benefits) Act 1997. R Lewis, above n 10.

${ }^{56}$ The Road Traffic (NHS Charges) Act 1999 was extended by Part III of the Health and Social Care (Community Health and Standards) Act 2003.

${ }^{57}$ The Ogden Tables, n 54, Appendix A para 12.
} 
continued to increase in line with the level of damages by more than double the rate of the rise in national earnings. It is frequently alleged that the continuing increases are due to the expansion of CFAs and claimants' ability to recover success fees and ATE insurance premiums. However, this remains a matter of controversy, and for present purposes the most that can be said is that there appears to be some correlation between the level of damages and legal fees. ${ }^{58}$

\section{CONCLUSION}

Although this article has highlighted only the main sources of information concerning personal injuries in the UK, these sources have often been overlooked by those who write on the law of tort. They are obviously of fundamental concern in any debate about the compensation culture, but they also inform many issues concerning the scope and operation of the narrow liability rules on which most writers focus. This study builds on our conviction that tort lawyers have a responsibility to inform themselves of the practical operation of the caselaw and statutory principles that they study, and their effects.

The conclusions we draw from the evidence we have presented can be summarised as follows. First, there is no evidence that the tort system has been flooded with an increasing number of personal injury claims in recent years. In fact the number of claims has been relatively stable since at least 1997-1998, the first year for which reliable CRU statistics are available. The swelling of the headline total claims figure from 2003 to 2005 is entirely due to a surge in disease claims prior to the closure of the Coal Health compensation schemes. In the same years, the number of accident claims actually fell. Nor can it be said that the introduction of CFAs and advertising for legal services has led to any measurable increase in claims during this period.

\footnotetext{
${ }^{58}$ A Morris, 'Conditional Fee Agreements in Northern Ireland: Godsend or Gimmick?' (2005) 56 NILQ 38.
} 
Secondly, and by way of contrast, consideration of a longer timeframe reveals that there has undoubtedly been a very substantial increase in the number of personal injury claims. Comparison of the CRU figures with the Pearson Commission's estimates from the 1970s shows an approximately three-fold rise in total claims numbers over 30 years, though not all categories of claim follow this pattern. Unfortunately there is no reliable data source which tracks the increase from year to year and therefore no means of determining whether it proceeded by steady increments or in fits and starts as a result of particular causative factors. It must be emphasised, however, that a mere rise in claims numbers is insufficient to establish the existence of a damaging compensation culture, as this insinuates that a significant proportion of claims are fraudulent, exaggerated or otherwise lacking in merit. We are not aware of any data that would support such a contention. The rise in claims numbers from the 1970s is equally consistent with there having been significant under-claiming at that time, with a subsequent increase in the proportion of those with genuine claims who chose to initiate legal action.

Finally, the average cost of compensation claims has undoubtedly risen in recent years at considerably more than the rate of inflation, whether in prices or earnings. This has been caused not only by changes in the legal rules governing the calculation of damages, but also by increases in lawyers' costs, and by the general increase in income levels. Much of the current debate about compensation culture stems from this rise in the cost of individual claims. Overall, what cannot be contested is that that debate would be better informed if attention were paid to the statistical information we already have about how the tort system actually operates. 